care assistants only, going onto specialist $\mathrm{OPH}$ and further up the ladder a medical nursing home and higher still, a specialist nursing home of the kind described above and ultimately psychiatric hopsital continuing care wards.

The following month the National Health Service and Community Care Act 1990 came into force and funding arrangements were transferred from the Department of Social Security to the local Social Services Department. The Manager of Social Services took the view that it was the exclustve responsibility of his department to decide where patients should be placed. He feared if it were left to other professionals, budgetary constraints might be exceeded. Consequently we lost the exclusive admission rights to the CCHA nursing home. Demented patients assessed elsewhere were placed in this CCHA nursing home. In our judgement all placements were not matched by the need for psychiatric nursing expertise.

Patients going through the admission/ assessment facility considered suitable for the CCHA facility are having to wait unduly long and are sometimes placed elsewhere. We lost a valuable opportunity to maintain working relationships between the two sectors of continuing care facility, one NHS managed and another charity nursing home managed.

Jouky, D. (1994) Services for Patients with Dementla. Editortal. Psychiatric Bullettn, 18, 389.

D. GASPAR, Northern Birmingham Mental Health Trust (East Sector), Little Bromwich Centre for Elderly Mental Health, Birmingham B10 9H

\section{A hidden cost of community care}

Sir: Before my mental hospital closed, I covered approximately 600 miles per month in my car. Since its closure and the dispersal of patients into small local units, my mileage now has jumped to 1200 and, given the geography of my catchment area, this amounts to approximately three sessions per week purely behind the wheel of my car. The workload, of course, does not decrease and, indeed, is increasing with supervision registers and the like. Community care for me, therefore, has resulted in more work having to be fitted into substantially less time which, of itself, is highly stressful.

In my old mental hospital I could go from ward to ward on foot and as it was relatively large I got a reasonable amount of exercise; not so now, my car is the only reasonable means 0 . transport to get me between the various dispersed units and the increase in mileage I cover is matched with a decrease in the amount of exercise I take.

Put these two factors together and community care for me and a great many of my colleagues, means a substantially increased risk of coronary heart disease and stroke. Is this really an acceptable price to pay for political correctness?

D. R: DAvies, Avalon Somerset NHS Trust, Rydon House, Cheddon Road, Taunton TA2 7AZ

\section{Sick doctor:}

Sir: We were glad to see that the issue of sick doctors is being addressed in the mental health field (Psychiatric Bulletin, April 1995, 19, 267).

This reminded us of one of the unstuffy gifts available from the College, and worn by some of its younger members, namely the 'Shrink Proof T-shirt.

We wonder whether this slogan gives the wrong message that psychiatrists are immune to mental health problems. What is required is an awareness that everyone may need help, and that psychiatrists are trained to prevent it.

In view of this, perhaps an updated slogan for the next batch of T-shirts should be 'Shrink-wrapped'!

E. J. Walter, Downend Clinic, Bristol BS16 5TW and N. D. MORGaN, Barrow Hospital, Bristol BS19 3SG

\section{Early retirement on mental health grounds}

Sir: I have been asked to prepare several reports on people in which early retirement on mental health grounds is being sought by the individual or his/her employer. Although such reports are requested after a prolonged episode of ill-health the individual concerned appears not to have been offered specialist psychiatric treatment. The most striking example was a man who had been psychotically depressed and on the verge of suicide.

Have other colleagues noticed the tendency?

ThOMAS PASTOR, Consultant Psychiatrist, Worthing Priority Care NHS Trust, Homefield, Lyndhurst Road, Worthing, West Sussex BN11 2HS 